\title{
Elevated primary productivity in the shallow Eastern Tethys during the Paleocene-Eocene Thermal Maximum
}

\author{
YING CUI ${ }^{1}$, DAVID NAAFS ${ }^{2}$, LILIANA CALDERON ${ }^{1}$, \\ MAURA DE PALMA ${ }^{1}$, ANTHONY GACHETTI ${ }^{1}$, ASHLEY \\ GREISS $^{1}$ AND SHIJUN JIANG ${ }^{3}$ \\ ${ }^{1}$ Montclair State University \\ ${ }^{2}$ University of Bristol \\ ${ }^{3}$ Hohai University \\ Presenting Author: cuiy@montclair.edu
}

Significant progress has been made on understanding the paleoclimatic evolution of the Paleocene-Eocene Thermal Maximum (PETM) in the major oceans, but the eastern Tethys remains poorly studied. As an important heat and moisture source in the low latitudes and large carbon sink as evidenced by the presence of organic rich black shales, the eastern Tethys may have played a significant role in carbon cycle dynamics and climate feedbacks. Here we report the first organic geochemistry data from a highly expanded shallow marine PETM section in Xinjiang Uygur Antonomous Region in Northwestern China. Our data indicate a low $\mathrm{C}_{29}$ hopane $\beta \beta /(\alpha \beta+\beta \alpha+\alpha \beta)$ ratio before and after the PETM, suggesting low levels of primary production in the surface waters with a background input of reworked older and more mature organic matter from the hinterland. At the onset of the PETM the $C_{29}$ hopane $\beta \beta /(\alpha \beta+\beta \alpha$ $+\alpha \beta)$ ratio rapidly increases, indicating an increased input of fresh organic matter, likely driven by a bloom of algae, which is consistent with an abrupt increase in TOC in the same samples. Nutrient proxies based on enrichment factors of $\mathrm{P}, \mathrm{Ba}, \mathrm{Co}$ and $\mathrm{Ni}$ and chemical index of weathering also show elevated values during the PETM, supporting the role of increased continental weathering and nutrient concentrations in stimulating primary productivity in the shallow eastern Tethys. We also note the occurrence of a diverse set of 2-methylhopanoids during the PETM interval only. Although the exact source organism(s) of 2methylhopanoids is debated, they likely reflect the expansion of cyano- and/or $\alpha$-proteobacteria in response to changes in nutrient cycling. New $n$-alkane compound-specific carbon isotope data show a 7 to $10 \%$ negative excursion during the PETM, slightly larger than those observed in bulk carbonate $(6.3 \%)$ and bulk organic matter $(5.5 \%)$ ). Taken together, our result indicate that the eastern Tethys experiences a major perturbation during the PETM. These data are consistent with Earth system model simulations with a large pulse of $\mathrm{CO}_{2}$ emission $(10,000 \mathrm{Gt} \mathrm{C}$ within 5,000 years) from the North Atlantic Igneous Province. 